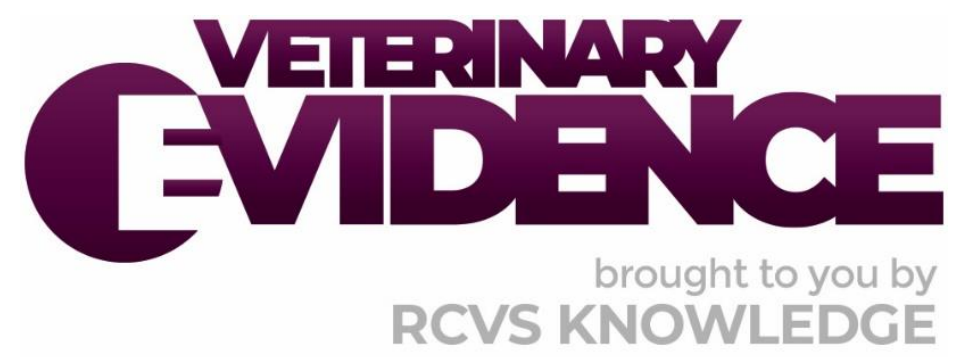

\title{
Does occurrence of ventricular arrhythmia reduce the survival rate in dogs with gastric dilatation volvulus (GDV)?
}

A Knowledge Summary by

Madeleine Thomson MRCVS ${ }^{1^{*}}$

\footnotetext{
${ }^{1}$ University of Surrey School of Veterinary Medicine, VSM Building, University of Surrey, Daphne Jackson Road, Guildford GU2 7AL

*Corresponding Author (madeleine.thomson@ntlworld.com)
}

ISSN: 2396-9776

Published: 25 Nov 2021

in: The Veterinary Evidence journal Vol 6, Issue 4

DOI: https://doi.org/10.18849/ve.v6i4.476

Reviewed by: Sam Double (BSc(Hons) VTS DipAVN(Medical)

RVN CertEd) and Dave Leicester (BVetMed PGCertSAECC MRCVS)

Next Review Date: 30 May 2023 


\section{PICO question}

Does occurrence of ventricular arrhythmia reduce the survival rate in dogs with gastric dilatation volvulus (GDV)?

\section{Clinical bottom line}

\section{Category of research question}

\section{Prognosis}

\section{The number and type of study designs reviewed}

The number and type of study designs that were critically appraised were three retrospective observational case-control studies (Brourman et al., 1996; Green et al., 2012; and Mackenzie et al., 2010) and one prospective, observational study (Aona et al., 2017)

\section{Strength of evidence}

Critical evaluation and appraisal of the papers that met the inclusion criteria provided only weak evidence to support the clinical question. This is due to the lack of recent (within the last 5 years) and specific (do the presence of cardiac arrythmias affect mortality of dogs with GDV) studies conducted on the subject. Additionally, more in-depth statistical analysis (e.g. P values and confidence intervals (CI)) may also help to determine the strength of association between the presence of ventricular arrythmia and survival rates.

However, there is room for further research to continue investigating the proposed hypothesis. Several of the evaluated studies were carried out more than 10 years before this Knowledge Summary was written, meaning that the knowledge and technology at the time may not be relevant to clinical practice today

\section{Outcomes reported}

Green et al. (2012) concluded that 'cardiac arrhythmia was not a prognostic indicator' for GDV.

Of the two papers (Mackenzie et al., 2010; and Brourman et al., 1996) that found a significant association between the development of cardiac arrhythmias (specifically, those of ventricular origin) and an increase in the mortality rates of dogs with GDV, one (Brourman et al., 1996) noted that a greater number of dogs that died prior to discharge were diagnosed with preoperative ventricular tachycardia, while the other (Mackenzie et al., 2010) found that the greatest mortality rate was among those dogs that developed postoperative ventricular tachycardia.

The final study, Aona et al. (2017), was the only paper to categorise and grade the ventricular arrhythmias using previously published scales. It was discovered that increased levels of cTn1 (cardiac troponin 1) made a dog more likely to develop a higher grade of arrhythmia, however, no association was found between the type or grade of arrhythmia and patient mortality

\section{Conclusion}

Taking into account the strength of evidence and the outcomes presented by the appraised studies the following conclusion has been drawn; although there is some evidence to suggest that ventricular tachycardia may be associated with an increase in mortality rates in patients with GDV, further research is required in order to make any further conclusions that may definitively answer the clinical question 


\section{How to apply this evidence in practice}

The application of evidence into practice should take into account multiple factors, not limited to: individual clinical expertise, patient's circumstances and owners' values, country, location or clinic where you work, the individual case in front of you, the availability of therapies and resources.

Knowledge Summaries are a resource to help reinforce or inform decision making. They do not override the responsibility or judgement of the practitioner to do what is best for the animal in their care.

\section{Clinical Scenario}

A 7 year old male neutered German Shepard presents during emergency 'out of hours' practice with gastric dilation volvulus (GDV). While hospitalised he is diagnosed, via electrocardiogram (ECG), with a ventricular arrhythmia secondary to the presenting complaint. Will this affect the expected prognosis and survival rate for this animal? Subsequently, does it affect the prognosis significantly enough that you would not recommend further treatment to the owner?

\section{The evidence}

From the studies appraised, there is some evidence to suggest that the development of ventricular arrhythmia may be associated with an increase in patient mortality. However, in general, the sample sizes were small and may not be easily extrapolated to a more general population. In addition, the literature reviewed varied significantly in both study objectives and methods. The majority of the reviewed literature was of high academic and clinical quality, however, one paper in particular (Mackenzie et al., 2010) contained poorly displayed information and confusing methodology.

Based solely on the acquired evidence from these four papers, there is insufficient evidence that the presence of ventricular arrhythmia alone may lead to decreased survival rates in dogs with GDV.

In conclusion, although there is some evidence to suggest that ventricular arrhythmia and, in particular, ventricular tachycardia, may be associated with increased mortality rates in patients with GDV. Further research is required in order to make any further conclusions that may definitively answer the clinical question.

\section{Summary of the evidence}

Green et al. (2012)

\begin{tabular}{|c|c|}
\hline Population: & $\begin{array}{l}\text { Dogs that were presented and diagnosed with GDV at a small animal } \\
\text { university teaching hospital. Cases were excluded if standard, } \\
\text { preoperative right lateral thoracic radiographs had not been } \\
\text { obtained. }\end{array}$ \\
\hline Sample size: & 101 dogs. \\
\hline Intervention details: & $\begin{array}{l}\text { - For included cases, the following information was obtained } \\
\text { from clinic medical records; breed, age, sex, time of } \\
\text { presentation to the clinic, respiratory status at presentation, } \\
\text { plasma lactate pre- and post-intravenous fluid therapy (IVFT) } \\
\text { administration, the presence of preoperative cardiac } \\
\text { arrhythmias and the method of decompression used. } \\
\text { - All radiographs were examined by a board certified } \\
\text { radiologist and the subsequent associated reports were } \\
\text { considered. }\end{array}$ \\
\hline
\end{tabular}




\begin{tabular}{|c|c|}
\hline & $\begin{array}{l}\text { - These radiographic abnormalities were noted to be } \\
\text { absent/present: esophageal dilation, micro-cardia, small } \\
\text { cranial vena cava, neoplasia (diffuse metastatic } \\
\text { disease/primary lung nodule/extra thoracic), aspiration } \\
\text { pneumonia, pulmonary bullae, sternal lymphadenopathy, } \\
\text { cardiomegaly, and pulmonary oedema. }\end{array}$ \\
\hline Study design: & Retrospective, single centre observational study. \\
\hline Outcome studied: & $\begin{array}{l}\text { Factors influencing survival to discharge: } \\
\text { - concurrent radiographic abnormalities; } \\
\text { - } \text { signalment; } \\
\text { - physiological parameters. }\end{array}$ \\
\hline $\begin{array}{l}\text { Main findings: } \\
\text { (relevant to PICO question): }\end{array}$ & $\begin{array}{l}\text { - In 6/101 (6\%) of cases, radiographs were taken due to } \\
\text { suspicion of cardiac disease; based on clinical exam findings, } \\
\text { auscultation or a previous history of cardiac pathology. } \\
\text { - Upon arrival, } 6 / 101 \text { (6\%) of the included dogs had a cardiac } \\
\text { arrhythmia. } \\
\text { - } 85 / 101 \text { ( } 84 \% \text { ) of dogs survived to discharge from the } \\
\text { hospital. } \\
\text { - } 16 / 101 \text { (16\%) of dogs did not survive to discharge from the } \\
\text { hospital. } \\
\text { Of these } 16 / 101 \text { dogs ( } 16 \% \text { ): } \\
\text { - } 12 / 16 \text { ( } 75 \% \text { ) of the dogs were euthanised prior to } \\
\text { surgery due to poor prognosis. Prognosis was } \\
\text { presumably assessed using results of ECG/clinical } \\
\text { exam but this was not made clear; } \\
\text { 2/16 (12.5\%) of the dogs were euthanised prior } \\
\text { to surgery due to owner financial constraints on } \\
\text { treatment; } \\
\text { 2/16 (12.5\%) of the dogs died during the } \\
\text { postoperative recovery period. } \\
\text { - } 4 / 85 \text { (5\%) of the surviving dogs presented with preoperative } \\
\text { ventricular arrhythmia. } \\
\text { 2/16 (13\%) of the dogs that did not survive presented with } \\
\text { preoperative ventricular arrhythmia. } \\
\text { Presence or absence of preoperative ventricular arrhythmia } \\
\text { was not decided to be a major contributing factor in patient } \\
\text { postoperative survival rates. }\end{array}$ \\
\hline Limitations: & $\begin{array}{l}\text { - Included cases were only taken from a single veterinary } \\
\text { hospital so may not be representative of other clinical } \\
\text { centres. } \\
\text { - It was not stated how the presence of ventricular arrhythmia } \\
\text { was definitively diagnosed or if all dogs were fully examined } \\
\text { for cardiac arrhythmias: } \\
\text { - It was not stated if any of the dogs underwent ECG, leaving } \\
\text { it unclear how the diagnosis of cardiac arrhythmia was } \\
\text { reached. } \\
\text { - It was not stated if the dogs diagnosed with cardiac } \\
\text { arrhythmia were the same dogs that also had suspected } \\
\text { cardiac disease prior to radiography: }\end{array}$ \\
\hline
\end{tabular}




\begin{tabular}{|l|l|}
\hline - These suspicions may have created bias in which only dogs \\
with suspected cardiac disease were fully investigated and \\
led to undiagnosed cardiac arrhythmias in the other dogs. \\
- It was not made clear if the two dogs (of the 16 dogs that did \\
not survive to discharge from hospital) diagnosed with \\
ventricular arrhythmia died due to euthanasia or succumbed \\
to their pathologies postoperatively: \\
If these dogs were euthanised due to poor prognosis and \\
subsequently excluded from the results, it could mean that \\
the effect of ventricular arrhythmia on post-operative \\
mortality is higher than recorded in the results of the study.
\end{tabular}

Aona et al. (2017)

\begin{tabular}{|c|c|}
\hline Population: & $\begin{array}{l}\text { Any dogs presented to the university hospital with GDV were } \\
\text { included. Study duration lasted from May } 2011 \text { to October } 2012 .\end{array}$ \\
\hline Sample size: & 22 dogs. \\
\hline Intervention details: & $\begin{array}{l}\text { - Diagnosis was made based on clinical exam/history, } \\
\text { signalment, presenting signs, right lateral radiograph. } \\
\text { Confirmation was made at point of surgery. } \\
\text { - Exclusion criteria included euthanasia or death prior to } \\
\text { surgery. } \\
\text { Blood samples were taken from every dog within } 30 \text { minutes } \\
\text { of presentation at the hospital: } \\
\text { o Further samples were taken subsequently every } 12 \\
\text { hours until hour 60, or the death of the animal; } \\
\text { Samples were analysed for cTn1, plasma lactate, and } \\
\text { N-terminal pro b-type natriuretic peptide } \\
\text { (NT-proBNP) levels. } \\
\text { - Dogs were monitored using ECG upon presentation and } \\
\text { throughout their entire surgery. Ventricular premature } \\
\text { complexes (VPCs) were measured according to a previously } \\
\text { published scale that was cited. } \\
6 \text { to } 18 \text { hours postoperatively, each dog underwent an ECG } \\
\text { performed by a board certified cardiologist. }\end{array}$ \\
\hline Study design: & Prospective observational study. \\
\hline Outcome studied: & $\begin{array}{l}\text { Study outcome was measured as whether the dogs survived to } \\
\text { discharge, and if not, whether they died or were euthanised. }\end{array}$ \\
\hline $\begin{array}{l}\text { Main findings: } \\
\text { (relevant to PICO question): }\end{array}$ & $\begin{array}{l}\text { - } 4 / 22 \text { (18\%) of dogs were treated with continuous rate } \\
\text { infusion (CRI) intravenous lidocaine during hospitalization. } \\
\text { - Upon presentation, } 4 / 22(18 \%) \text { of dogs had ventricular } \\
\text { arrhythmias (it was not stated if these were the same dogs } \\
\text { given CRI lidocaine, but one would suspect). } \\
\text { - Over the course of their hospital stay, } 15 / 22(68 \%) \text { of the } \\
\text { dogs developed ventricular arrhythmias. } \\
\text { - The ventricular arrhythmias identified were categorised as } \\
\text { follows: } \\
\quad \text { single ventricular premature complex (VPC) in } 9 / 15 \\
(60 \%) \text { dogs (Grade } 1) \text {; }\end{array}$ \\
\hline
\end{tabular}




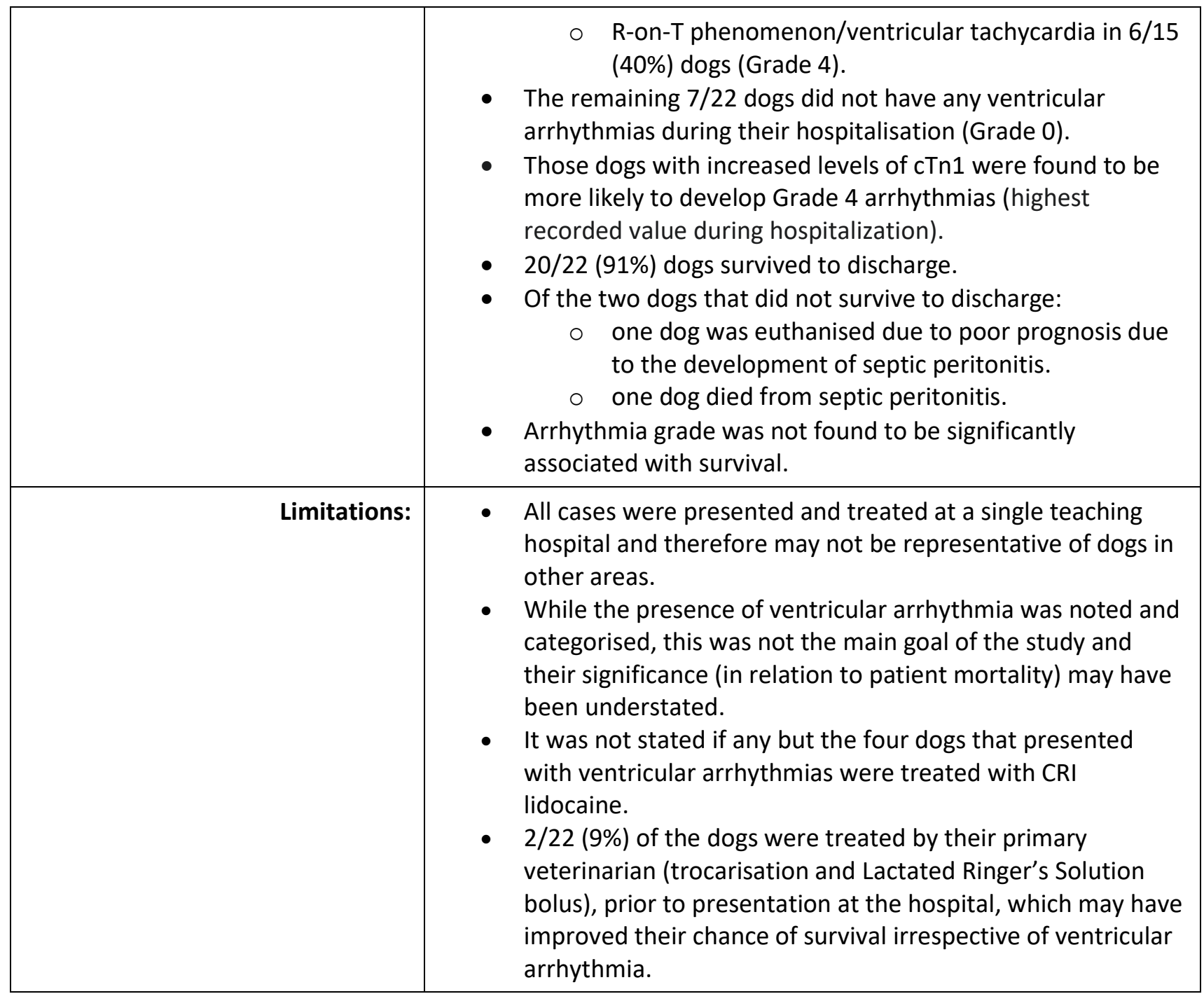

Mackenzie et al. (2010)

\begin{tabular}{|c|c|}
\hline Population: & $\begin{array}{l}\text { Dogs diagnosed with GDV between } 2000-2004 \text { that were } \\
\text { anaesthetised for surgery. Study centre not stated. }\end{array}$ \\
\hline Sample size: & 306 dogs. \\
\hline Intervention details: & $\begin{array}{l}\text { - The medical records of all dogs were assessed for the } \\
\text { following factors: signalment (age/breed/sex), time to } \\
\text { presentation, time from presentation to surgery, presence } \\
\text { of pre and postoperative cardiac arrhythmias, } \\
\text { anesthetic/surgical duration and incidence of gastric/splenic } \\
\text { injury. } \\
\text { - A diagnosis of GDV was made based on preoperative, right } \\
\text { sided lateral radiographs. } \\
\text { - Biochemistry/hematology, blood count results and any } \\
\text { treatments administered preoperatively were not evaluated } \\
\text { as part of this study. } \\
\text { - The presence of cardiac arrhythmias was noted following } \\
\text { abnormalities in the patients' pulse, ECG or both. } \\
\text { - Similar, but not identical, anesthetic protocol was used in all } \\
\text { dogs. }\end{array}$ \\
\hline
\end{tabular}




\begin{tabular}{|c|c|}
\hline & $\begin{array}{l}\text { The overall mortality rate of the study was defined as the } \\
\text { number of dogs that died or were euthanised intra or } \\
\text { postoperatively, compared to the total number of dogs that } \\
\text { were anesthetised. } \\
\text { The postoperative mortality rate was defined as the number } \\
\text { of dogs that died or were euthanised between the end of } \\
\text { anesthesia and discharge from hospital, of all dogs that } \\
\text { survived anesthesia. }\end{array}$ \\
\hline Study design: & Retrospective observational study. \\
\hline Outcome studied: & $\begin{array}{l}\text { Do these conditions/factors/procedures affect the overall and } \\
\text { postoperative mortality rates: } \\
\text { - cardiac arrhythmias; } \\
\text { - splenectomy; } \\
\text { - partial gastrectomy; } \\
\text { - time to presentation; } \\
\text { - anaesthetic time; } \\
\text { - surgical time. }\end{array}$ \\
\hline $\begin{array}{l}\text { Main findings: } \\
\text { (relevant to PICO question): }\end{array}$ & $\begin{array}{l}\text { - Overall mortality rate was } 30 / 306(9.8 \%) \\
\text { Of the } 12 / 30(40 \%) \text { dogs that died intraoperatively: } \\
\text { - } 4 / 12(33 \%) \text { died naturally } \\
\text { due to poor prognosis. } \\
\text { - Postoperative mortality rate was } 18 / 294(6.1 \%) \text {. } \\
\text { - All cardiac arrhythmias recorded during the study were of } \\
\text { ventricular origin. } \\
\text { 16/147 ( } 11 \%) \text { of the dogs were diagnosed with preoperative } \\
\text { cardiac arrhythmias. } \\
\text { Of these: } \\
\text { - } 12 / 16 \text { were intermittent ventricular arrhythmias } \\
\text { (IVA) } \\
\text { - } 4 / 16 \text { were ventricular tachycardias. } \\
\text { cardiac arrhythmias. } \\
\text { Of these: } \\
\text { - } 105 / 133 \text { were IVA; } \\
\text { - } 28 / 133 \text { were ventricular tachycardias. } \\
\text { - } 5 / 133 \text { (3.8\%) of the dogs within this population died } \\
\text { Dogs with preoperative cardiac arrhythmias were associated } \\
\text { with a higher overall mortality rate than those without } \\
\text { preoperative cardiac arrhythmias. } \\
\text { Dogs with postoperative ventricular tachycardia were } \\
\text { associated with a higher overall mortality rate compared to } \\
\text { those without postoperative ventricular tachycardia. }\end{array}$ \\
\hline Limitations: & $\begin{array}{l}\text { - It was not explicitly stated where the medical records were } \\
\text { collected from. } \\
\text { Blood test results (blood count/biochemistry/haematology) } \\
\text { were not evaluated as part of the study, and it is therefore } \\
\text { unknown if there were any concurrent trends among the } \\
\text { results that could have influenced the results of the study. }\end{array}$ \\
\hline
\end{tabular}




\begin{tabular}{|l|l|}
\hline - The results were poorly presented, with information missing \\
and it is not clear where some numerical values came from. \\
- Incomplete medical records and the retrospective nature of \\
the study means that not all aspects of the patients' \\
treatment could be evaluated.
\end{tabular}

\begin{tabular}{|c|c|}
\hline \multicolumn{2}{|l|}{ Brourman et al. (1996) } \\
\hline Population: & $\begin{array}{l}\text { Dogs that underwent surgical correction of suspected GDV at two } \\
\text { veterinary centres (one university hospital and one private practice) } \\
\text { between } 1988 \text { and } 1993 .\end{array}$ \\
\hline Sample size: & 137 dogs. \\
\hline Intervention details: & $\begin{array}{l}\text { - Surgical correction predominantly involved repositioning } \\
\text { and decompression of the stomach. } \\
\text { - Some animals required further surgical procedures such as } \\
\text { gastric resection or splenectomies. } \\
\text { O These factors were evaluated to determine any } \\
\text { possible association with patient mortality. } \\
\text { - All dogs were monitored from admission to discharge, using } \\
\text { ECG's and comprehensive blood analysis } \\
\text { (hematology/biochemistry/WBC counts). } \\
\text { - The presence of cardiac arrhythmia was } \\
\text { determined/confirmed by ECG following clinical exam. } \\
\text { - Dogs that died at any point during 8hospitalisation were } \\
\text { included in mortality calculations. } \\
\text { - Fisher's Exact test (Handbook of Biological Statistics, 2014) } \\
\text { was used to determine the strength of association between } \\
\text { significant factors and mortality. Where P < } 0.05 \text {, there was } \\
\text { considered to be a considerable association. }\end{array}$ \\
\hline Study design: & Retrospective, multi-centre observational study. \\
\hline Outcome studied: & $\begin{array}{l}\text { - The association between identified risk factors and mortality } \\
\text { in dogs with GDV. } \\
\text { - Differences in treatments between two clinical practices and } \\
\text { the effects on patient mortality. }\end{array}$ \\
\hline $\begin{array}{l}\text { Main findings: } \\
\text { (relevant to PICO question): }\end{array}$ & $\begin{array}{l}\text { - 24/137 (18\%) dogs died or euthanised due to poor prognosis } \\
\text { during hospitalisation: } \\
\text { o } 18 / 24 \text { dogs died postoperatively; } \\
\circ 5 / 24 \text { dogs were euthanised during surgery; } \\
01 / 24 \text { was euthanised postoperatively. } \\
\text { - } \quad 113 / 137 \text { ( } 82 \% \text { ) of cases seen survived to discharge. } \\
\text { - No blood biochemistry or hematology parameters were } \\
\text { found to have significant associations with mortality. } \\
\text { - 92/137 (67\%) of the total cases were found to have } \\
\text { developed a cardiac arrhythmia during hospitalisation. } \\
\text { 16/92 of these were preoperative, } 28 / 92 \text { occurred } \\
\text { intraoperatively and } 48 / 92 \text { were postoperative. }\end{array}$ \\
\hline
\end{tabular}




\begin{tabular}{|c|c|}
\hline & $\begin{array}{l}\text { - Of the } 16 / 92 \text { that occurred preoperatively: } \\
\quad \begin{array}{l}6 / 16 \text { (38\%) of those died during hospitalisation; } \\
\circ \\
121 / 137 \text { ( } 88 \%) \text { of the dogs did not present with } \\
\text { preoperative cardiac arrythmias; } \\
\text { comparatively, } 18 / 121 \text { (15\%) dogs without } \\
\text { preoperative arrhythmias died during } \\
\text { hospitalisation. }\end{array} \\
\text { - Of the 28/92 that occurred intraoperatively, seven dogs } \\
\text { died. } \\
\text { - Of the } 48 / 92 \text { that occurred postoperatively, six dogs died. } \\
\text { Overall mortality for dogs with cardiac arrhythmias was } \\
\text { found to be } 22 \% \text {. } \\
\text { Mortality rates between the two centres were not } \\
\text { found to be significantly different. } \\
\text { - The use of antiarrhythmics was not associated with a } \\
\text { significant reduction in mortality at either clinic. }\end{array}$ \\
\hline Limitations: & $\begin{array}{l}\text { - Cardiac arrhythmias were not investigated further } \\
\text { postdiagnosis, or categorised according to origin. } \\
\text { - Factors such as age, clinical history and prior cardiac disease } \\
\text { were not considered during the study. } \\
\text { - Although these was found to be a significant } \\
\text { association between dogs that developed } \\
\text { preoperative arrhythmias and increased mortality; } \\
\text { certain dogs may be predisposed to this condition, } \\
\text { as well as more vulnerable to mortality should they } \\
\text { develop an arrhythmia. } \\
\text { - It was not stated how the diagnosis of GDV was made. } \\
\text { Significant advances in medical technology have been made } \\
\text { since this paper was published and as such, the results may } \\
\text { not be as relevant to clinical practice today as they were at } \\
\text { the time of the study. }\end{array}$ \\
\hline
\end{tabular}

\section{Appraisal, application and reflection}

Relevant to this Knowledge Summary, four papers were found which investigated the effects of ventricular arrhythmias on the mortality rates of dogs with GDV. Of these, three were retrospective, observational, case control studies (Brourman et al., 1996; Green et al., 2012; and Mackenzie et al., 2010) and one was a prospective observational study (Aona et al., 2017).

The first retrospective observational study (Green et al. 2012) reviewed the presence of radiographic abnormalities and their effects on mortality in dogs with GDV. Logistic regression analysis was used to evaluate the risk that presenting clinical signs (including presence of ventricular arrythmia) may have on chance of survival to discharge.

Only $2 / 16(13 \%)$ of the dogs that died or were euthanised during their hospitalisation were diagnosed with ventricular arrhythmias and it was concluded that the presence of ventricular arrhythmia was not strongly associated with increased patient mortality rates. Neither $\mathrm{P}$ value or confidence intervals $(\mathrm{Cl})$ were stated for ventricular arrhythmia, and it was unknown if they were simply not calculated or that they were not found to be of statistical relevance (e.g. $\mathrm{P}<0.05$ or $\mathrm{Cl}>95 \%$ ). Calculating these values would give a better indication of the strength of evidence that the presence of ventricular arrhythmia may affect survival to discharge.

Ventricular tachycardia can be caused by both extra cardiac pathologies as well as primary heart disease, which can often be seen on thoracic radiographs (Rishniw, 2020). In the paper by Green et al. (2012), 6/101 
(6\%) of the cases included in the study were radiographed upon admission due to suspected cardiac disease but it was not stated what proportion, if any, of these dogs presented with or developed ventricular tachycardia during hospitalisation. There may have been bias present, where only dogs with suspected cardiac disease were fully examined for the presence of cardiac arrhythmias, meaning that other dogs may have developed arrhythmias that went undiagnosed. It was also not stated how a diagnosis of ventricular arrhythmia was made in the $6 \%$ of dogs that presented with the condition. However, the paper itself was detailed and well-presented, and the results of the study were clear and logical.

Mackenzie et al. (2010), a retrospective, observational study, evaluated the factors significantly affecting overall and postoperative mortality rates in dogs anaesthetised for surgery to correct GDV. The study found that preoperative cardiac arrhythmias of any origin; as well as postoperative ventricular tachycardia (not concurrently) were associated with a higher overall mortality rate among the 306 cases that were evaluated. Statistical analysis was not performed on the collected data, meaning that the strength of association between ventricular arrhythmia and mortality rate was not able to be properly evaluated.

Furthermore, incomplete medical records and the retrospective nature of the study may mean that some aspects of the included cases could not be properly analysed. Additionally, there was confusion as to the origin of some of the figures presented in the results section of the paper as well as the conclusion that was drawn with regards to the incidence of preoperative intermittent ventricular arrhythmias. It was also stated that preoperative IVA's were associated with 'much higher mortality rates,' but only provided a P value to support this statement, rather than the number of dogs with preoperative IVA that died.

The third retrospective observational study that was evaluated (Brourman et al., 1996) looked at factors affecting mortality in the perioperative period of dogs admitted to either a university hospital or a private veterinary clinic with GDV. Only those cases that underwent surgical correction (which predominantly involved decompression and repositioning of the stomach) were included in the study. Fisher's Exact test was used to determine the strength of association between patient factors and mortality, with $\mathrm{P}<0.05$ indicating that a significant association existed.

Of the included cases, $92 / 137(67 \%)$ were found to have developed a cardiac arrhythmia during their hospitalisation; of which 20/92 (22\%) died during the perioperative period. The mortality rate for those dogs that developed preoperative cardiac arrhythmias was found to be $35 / 92(38 \%)$, more than double that of the mortality rate of dogs without preoperative cardiac arrhythmias 18/121 (15\%). Preoperative cardiac arrhythmias were found to have a $P$ value of greater than 0.05 , indicating a considerable association with patient mortality. The results did not differ significantly between the two study centers. Although it would have been a useful tool for evaluating the strength of evidence presented by this paper. Confidence intervals were not calculated in this study.

Both hematology and biochemistry parameters were monitored for every dog involved in the study, but none were found to have any impact on patient mortality or the chances of developing cardiac arrhythmias.

While all instances of cardiac arrhythmia were diagnosed through clinical exam and electrocardiography, there was no further investigation conducted into the origin or categories of arrhythmia present. Additional clinical research could aid in determining which types of cardiac arrhythmia are significantly associated with increased mortality in dogs with GDV.

The remaining paper, a prospective, observational study (Aona et al., 2017) was the most recent study conducted on the subject; and evaluated electrocardiography and cardiac biomarker concentrations taken from dogs admitted to a university hospital for suspected GDV from May 2011 to October 2012. Dogs that died prior to surgery or were euthanised were excluded from the study. Ventricular arrhythmias were identified and graded using a previously published scale of $0-4$, with 0 representing the absence of VPCs (ventricular premature complexes) and 4 being ventricular tachycardia. Of the 15 dogs that developed ventricular arrhythmias, nine were categorised as Grade 1 and six were categorised as Grade 4.

A strong association was found between increased concentrations of cTn1 and the likelihood of a patient developing a Grade 1 or 4 ventricular arrhythmia. The $P$ values for dogs with Grade 1 and Grade 4 were found to be $\mathrm{P}<0.001$ and $\mathrm{P}=0.002$ respectively, showing a strong correlation between these data sets. 
However, arrhythmia grade was not found to be a significant contributing factor in patient survival following surgical correction of GDV. It is unknown whether $P$ values were calculated to show the strength of correlation between presence of ventricular arrhythmia and mortality rate. Doing so may have helped to statistically show the strength of evidence of the study in relation to the PICO question.

Categorical data in more than two categories (arrhythmia grade) was compared using both chi-squared and Friedman tests. Biomarker concentrations were classed as continuous variables and compared using Pearson's and Spearman's rank correlations.

While the design of the study was well laid out and thorough, the sample size was not particularly large, and as such may not have provided results that were as accurate as they could have been. Additionally, it was not stated whether the presence of ventricular arrhythmia alone was considered a major factor in overall patient mortality and survival post discharge.

Large breed, deep-chested dogs have been found to be statistically more likely to develop GDV and indeed, in the papers where breed was recorded, it was these dogs that were overrepresented. It should be noted that smaller dogs may still develop GDV, although not with the same frequency (PDSA, 2020).

In conclusion, while some of the evaluated papers provided evidence that may suggest ventricular tachycardia has an association with increased patient mortality in dogs with GDV, there are several weaknesses in the methods and results that prevent conclusive assumptions from being made. Primarily, the cases included in the appraised studies, with the exception of Brourman et al. (1996), were collected from a single hospital. For the conclusion of this Knowledge Summary to be applicable to small animal general practice in the UK, it would be preferable that this be drawn from the largest population and geographical area possible.

All but one of the papers (Mackenzie et al., 2010) used 137 dogs or fewer, with only 22 dogs being included in the study conducted by Aona et al. (2017). As such, any confounding factors present are more likely to skew the results obtained by the study, and it is significantly more difficult to extrapolate to the general population on which the outcome of the study was to be applied.

It could also be assumed, as a general rule, that veterinary university hospitals are better equipped than most small animal clinics, meaning that the dogs may be more likely to survive to discharge at these hospitals, irrespective of their cardiac status.

There is some evidence to suggest that the presence of preoperative ventricular arrhythmias may be associated with reduced survival rate in dogs presented for GDV, but further research on the subject is required to definitively prove this hypothesis. A conclusive answer to this PICO question could allow clinicians in practice to better predict survival rates for patients and provide more accurate information to owners regarding the chances of success for continued treatment of their animal.

Further research on the subject may include larger, multi-centre observational studies with a focus on diagnosing and monitoring cardiac arrythmias in dogs diagnosed with GDV. A larger number of cases included would allow for more accurate and reliable results, while a multi-center study would be more reflective of the wider population, rather than just that of a single centre study. Further, in-depth statistical analysis may also be of use in determining strength of correlation between ventricular arrhythmias and mortality rates in dogs with GDV. 


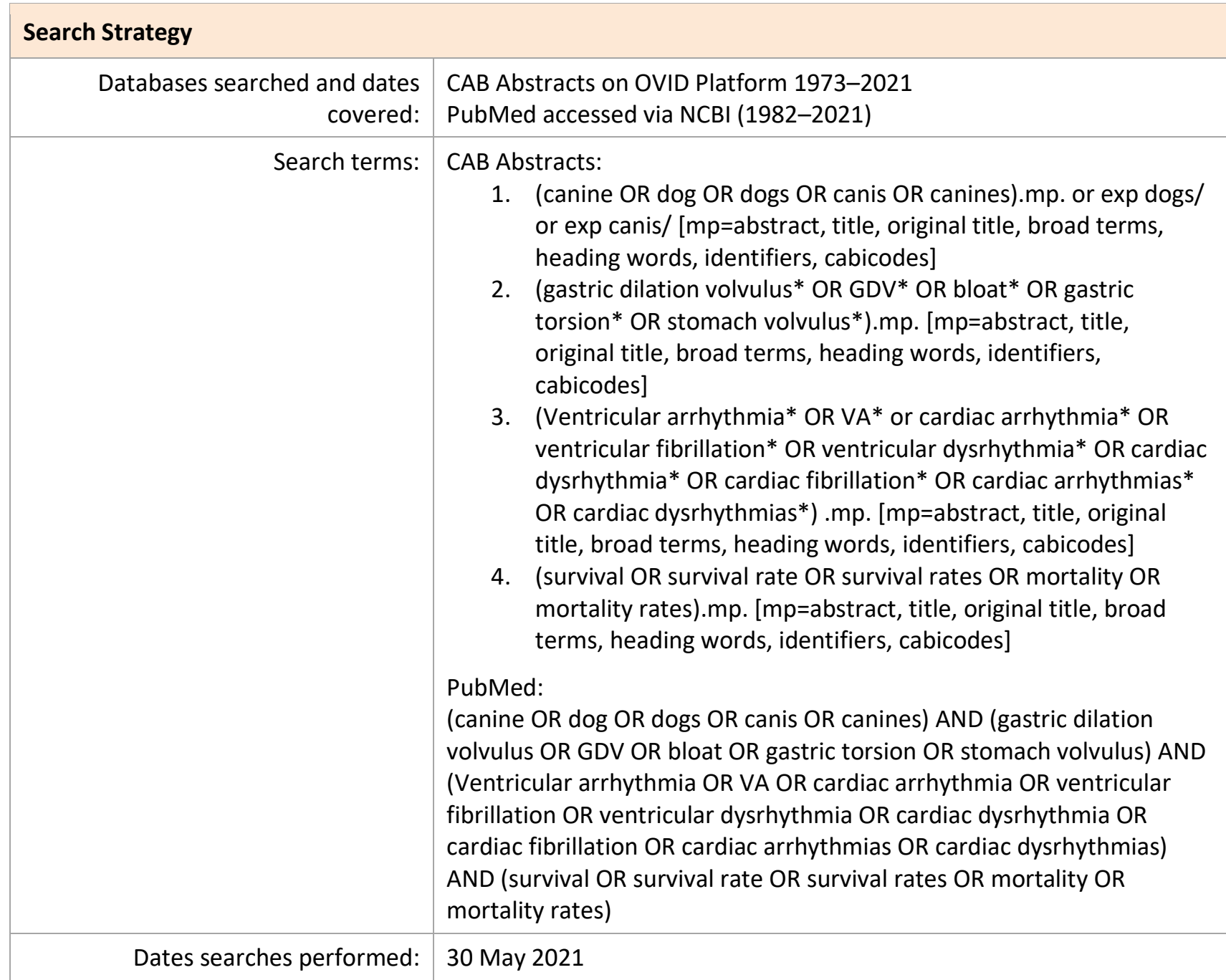

\section{Exclusion / Inclusion Criteria}

The main aim was to ensure that the literature used in the Knowledge Summary was as relevant to the PICO question as possible, and that the results would be applicable to the wider population in small animal general practice. Since the PICO question was specific to dogs, any paper that studied non-canine patients was excluded. Differences in surgical technique used was not considered when reviewing the literature for this Knowledge Summary as it is not within the scope of, or relevant to, the PICO question.

\begin{tabular}{|l|l|l|}
\hline Exclusion: & - Non-canine patients \\
& - Single case reports \\
& - Duplicate \\
& - Non-observational studies \\
& - Full text not available \\
\hline Inclusion: & - Canine patients \\
& - Peer reviewed publication \\
& - English language \\
& - Reporting the survival rates of dogs with GDV with or without \\
& \\
& - & ventricular arrhythmia \\
&
\end{tabular}




\begin{tabular}{|c|c|c|c|c|c|c|c|c|}
\hline \multicolumn{9}{|c|}{ Search Outcome } \\
\hline Database & $\begin{array}{c}\text { Number of } \\
\text { results }\end{array}$ & $\begin{array}{c}\text { Excluded - } \\
\text { Non-canine } \\
\text { patients }\end{array}$ & $\begin{array}{c}\text { Excluded - } \\
\text { Duplicate }\end{array}$ & $\begin{array}{c}\text { Excluded - } \\
\text { Non-GDV/Cardiac } \\
\text { arrhythmia }\end{array}$ & $\begin{array}{c}\text { Excluded - } \\
\text { Non-observational } \\
\text { studies }\end{array}$ & $\begin{array}{l}\text { Excluded - } \\
\text { Full text not } \\
\text { available }\end{array}$ & $\begin{array}{l}\text { Excluded - } \\
\text { Paper } \\
\text { available in } \\
\text { English }\end{array}$ & $\begin{array}{c}\text { Total } \\
\text { relevant } \\
\text { papers }\end{array}$ \\
\hline CAB Abstracts & 24 & 0 & 4 & 5 & 6 & 1 & 4 & 4 \\
\hline PubMed & 13 & 0 & 2 & 1 & 5 & 1 & 0 & 4 \\
\hline \multicolumn{8}{|c|}{ Total relevant papers when duplicates removed } & 4 \\
\hline
\end{tabular}




\section{CONFLICT OF INTEREST}

The author declares no conflicts of interest.

\section{REFERENCES}

1. Aona, B.D., Rush, J.E., Rozanski, E.A., Cunningham, S.M., Sharp, C.R. \& Freeman, L.M.

(2017). Evaluation of echocardiography and cardiac biomarker concentrations in dogs with gastric dilatation volvulus. Journal of Veterinary Emergency and Critical Care. 27(6), 631-637.

DOI: https://doi.org/10.1111/vec.12667

2. Brourman, J.D., Schertel, E.R., Allen, D.A., Birchard, S.J. \& DeHoff, W.D. (1996). Factors associated with perioperative mortality in dogs with surgically managed gastric dilatation-volvulus: 137 cases (19881993). Journal of the American Veterinary Medical Association. Available at: https://pubmed.ncbi.nlm.nih.gov/8675474/ [Accessed 11 Dec 2020].

3. Green, J.L., Cimino Brown, D. \& Agnello, K.A. (2012). Preoperative thoracic radiographic findings in dogs presenting for gastric dilatation-volvulus (2000-2010): 101 cases. Journal of Veterinary Emergency and Critical Care. 22(5), 595-600. DOI: https://doi.org/10.1111/i.1476-4431.2012.00802.x

4. Mackenzie, G., Barnhart, M., Kennedy, S., DeHoff, W. \& Schertel, E. (2010). A retrospective study of factors influencing survival following surgery for gastric dilatation-volvulus syndrome in 306 dogs. Journal of the American Animal Hospital Association. 46(2), 97-102. DOI: https://doi.org/10.5326/0460097

5. PDSA. (2020). GDV (Gastric Dilation Volvulus). [online] Available at: https://www.pdsa.org.uk/takingcare-of-your-pet/pet-health-hub/conditions/gdv-gastric-dilatation-volvulus-in-dogs [Accessed 1 Jan 2021].

6. Rishniw, M. (2020). Ventricular Tachycardia. Vetlexicon Canis powered by Vetstream. [online] Available at: https://www.vetstream.com/treat/canis/diseases/ventricular-tachycardia [Accessed 29 Dec 2020]. 


\section{EVIIDEFeE

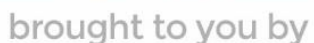 \\ RCVS KNOWLEDGE}

\section{Intellectual Property Rights}

Authors of Knowledge Summaries submitted to RCVS Knowledge for publication will retain copyright in their work, and will be required to grant RCVS Knowledge a non-exclusive license of the rights of copyright in the materials including but not limited to the right to publish, re-

publish, transmit, sell, distribute and otherwise use the materials in all languages and all media throughout the world, and to license or permit others to do so.

\section{Disclaimer}

Knowledge Summaries are a peer-reviewed article type which aims to answer a clinical question based on the best available current evidence. It does not override the responsibility

of the practitioner. Informed decisions should be made by considering such factors as individual clinical expertise and judgement along with patient's circumstances and owners' values. Knowledge Summaries are a resource to help inform and any opinions expressed within the Knowledge Summaries are the author's own and do not necessarily reflect the view of the RCVS Knowledge. Authors are responsible for the accuracy of the content. While the

Editor and Publisher believe that all content herein are in accord with current recommendations and practice at the time of publication, they accept no legal responsibility

for any errors or omissions, and make no warranty, express or implied, with respect to material contained within.

For further information please refer to our Terms of Use.

RCVS Knowledge is the independent charity associated with the Royal College of Veterinary Surgeons (RCVS). Our ambition is to become a global intermediary for evidence based veterinary knowledge by providing access to information

that is of immediate value to practicing veterinary professionals and directly contributes to evidence based clinical decision-making.

https://www.veterinaryevidence.org/

RCVS Knowledge is a registered Charity No. 230886.

Registered as a Company limited by guarantee in England and Wales No. 598443.

Registered Office: Belgravia House, 62-64 Horseferry Road, London SW1P 2AF

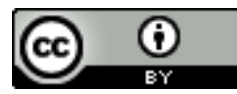

This work is licensed under a Creative Commons Attribution 4.0 International License 